\title{
Burden of cancer attributable to tobacco smoke in Japan in 2015
}

\author{
Kota Katanoda ${ }^{1, *}$, Mayo Hirabayashi², Eiko Saito', Megumi Hori', Sarah K. Abe², Tomohiro Matsuda ${ }^{3}$, Manami Inoue ${ }^{2}$; \\ the Cancer PAF Japan Collaborators \\ ${ }^{1}$ Division of Cancer Statistics Integration, Center for Cancer Control and Information Services, National Cancer Center, Tokyo, Japan; \\ ${ }^{2}$ Division of Prevention, Center for Public Health Sciences, National Cancer Center, Tokyo, Japan; \\ ${ }^{3}$ National Cancer Registry Section, Center for Cancer Registries, Center for Cancer Control and Information Services/Office of International \\ Affairs, Strategic Planning Bureau National Cancer Center, National Cancer Center, Tokyo, Japan.
}

\begin{abstract}
Tobacco is the greatest single cause of many non-communicable diseases, including cancer. We calculated the proportion of cancer incidence and mortality in 2015 attributable to tobacco smoking and exposure to secondhand smoke (SHS). Data on the prevalence of active smoking were derived from the 2005 Japanese National Health and Nutrition Survey by age group and gender. For SHS exposure prevalence, data from a nationwide cross-sectional survey from 2004-2005 were used. Based on standard formulas, population attributable fractions (PAFs) for each cancer causally associated with active smoking, namely the oral cavity and pharynx, esophagus, stomach, colon, rectum, liver, pancreas, nasal, larynx, lung, uterine cervix, kidney, renal pelvis and ureter, bladder, and acute myeloid leukemia, were calculated for each sex and age group and aggregated to obtain the PAF among total cancer incidence and mortality. For SHS exposure, PAFs for lung cancer and total cancer were calculated using the same method. For Japan in 2015, 145,765 new cancer cases and 72,520 cancer deaths, corresponding to a PAF of $15.2 \%$ for total cancer incidence and $19.6 \%$ for total cancer mortality, were attributable to active tobacco smoking. For SHS exposure, $0.5 \%$ of total cancer incidence and $0.7 \%$ of total cancer mortality in 2015 were attributable. Tobacco is still one of the major causes of cancer in Japan.
\end{abstract}

Keywords: cancer, tobacco smoke, secondhand smoke, population attributable fraction, Japan

\section{Introduction}

Tobacco smoking is the greatest single preventable cause of cancer (1). Globally, there are estimated to be $1,820,000$ cancer deaths every year due to active smoking and 125,000 cancer deaths due to secondhand smoke (SHS) exposure (2). The incidence of tobacco-caused diseases is particularly high in East Asia. Japan ranks sixth in the world for tobacco consumption (3). Smoking prevalence among men aged $30-49$ years is $37 \%$ (4). The latest estimates on the population-attributable fractions (PAFs) of tobacco-related cancers in Japan were released in $2005(125,898$ cases for active smoking and 4,152 cases for SHS exposure) (5). With regard to active smoking, other studies have reported similar estimates by including non-cancer diseases attributable to smoking, using data obtained in 2005 (6), 2007 (7), and 2008 (8). These estimates are now somewhat out of date, however, and their selection of smoking-related diseases was based on studies conducted mostly among Westerners.

In 2016, the Committee on Health Effects of Smoking of the Ministry of Health, Labour and Welfare (MHLW) released a comprehensive report on health consequences attributable to smoking (9). Following the U.S. Surgeon General's Report (10), this report made comprehensive and systematic assessments of the causal relationships between smoking and disease in the Japanese population. This report and studies conducted before and after it included meta-analyses and pooled analyses of large-scale cohort studies performed in Japanese populations, which aimed to explore the association between active smoking and head and neck cancers (11), bladder cancer (12), hematologic malignancies (13), cervical cancer (14), and colorectal cancer (15), and the association between SHS exposure and lung cancer (16). Thanks to these studies, it is now possible to select smoking-related diseases specific to the Japanese population and to calculate their RRs using more representative data. Additionally, the prevalence of smoking in Japanese, particularly among men, has declined over the past 10 years $(4,17)$, which is likely a major contributor to changes in the estimates of smoking-attributable cancer incidence and mortality.

Therefore, this study aimed to estimate the proportion of cancer incidence and mortality in 2015 attributable to active tobacco smoking and exposure to SHS. 


\section{Materials and Methods}

\section{Cancers associated with tobacco smoking}

The International Agency for Research on Cancer (IARC) confirmed that tobacco smoking, SHS exposure, and smokeless tobacco were all reaffirmed as carcinogenic to humans (Group 1) (18). There are major global and domestic comprehensive assessments: an IARC monograph published in 2012 (19), a report of the US Surgeon General in 2014 (20), and a domestic assessment by the Research Group for the Development and Evaluation of Cancer Prevention Strategies in Japan (21). In Japan, these assessments were further comprehensively evaluated and integrated into the most recent report by the Committee on Health Effects of Smoking in 2016 (9). Therefore, we applied the target cancers causally associated with tobacco smoking concluded by this evaluation, namely those that showed sufficient evidence for a positive association with tobacco smoking and for which RR estimates in Japan were available, including cancer of the oral cavity and pharynx, esophagus, stomach, colon, rectum, liver, pancreas, nasal cavity and paranasal sinuses, larynx, lung, cervix uterine, kidney, renal pelvis and ureter, urinary bladder and acute myeloid leukemia. For SHS exposure, the only cancer retained in the analysis was lung cancer among never-smokers.

\section{Prevalence of tobacco smoking}

The data on smoking status were derived from the Japanese National Health and Nutrition Survey (JNHNS) from 2005 (22), which presents the proportion of current, former, and never smokers by sex and age group. Smoking prevalence from year 2000 of the JNHNS (23) was further used for sensitivity analysis. Sex- and agegroup-specific prevalence of tobacco smoking in Japan in 2005 is shown in Table 1. For SHS exposure prevalence, data from a nationwide cross-sectional survey from 2004-2005 funded by Grants-in-aid from Ministry of Health, Labour, and Welfare were used (24). This survey collected data on the proportion of non-smoking men and women who were exposed to SHS. The two possible exposure locations considered were home and work. The sex- and age-group-specific prevalence (\%) of SHS exposure in Japan in 2005 is shown in Table 2.

\section{Cancer incidence and mortality in Japan in 2015}

Cancer incidence data in 2015 were estimated using the annual estimate of cancer incidence in 2013 by the Monitoring of Cancer Incidence in Japan (25). This estimate was done using an age and period spline model, a method which is used for short-term projections for cancer incidence in Japan (26). The sex- and age-specific incidence data for target cancers were coded by the International Statistical Classification of Diseases and Related Health Problems, $10^{\text {th }}$ edition (ICD-10), using the morphology code of the International Classification of Disease for Oncology, $3^{\text {rd }}$ edition (ICD-O-3).

The data on cancer mortality statistics from 2015 were obtained from the vital statistics of Japan (27). We sourced sex- and age-specific mortality data by cause of death from the Health, Labour, and Welfare Statistics Association (28). Similar to the cancer incidence data, 4-digit ICD-10 codes were used to classify the cause of death

Table 1. Sex- and age-group-specific prevalence of tobacco smoking in Japan in 2005

\begin{tabular}{|c|c|c|c|c|c|c|c|c|c|c|c|c|}
\hline \multirow{3}{*}{ Age at exposure } & \multicolumn{6}{|c|}{2005} & \multicolumn{6}{|c|}{2000} \\
\hline & \multicolumn{3}{|c|}{ Men } & \multicolumn{3}{|c|}{ Women } & \multicolumn{3}{|c|}{ Men } & \multicolumn{3}{|c|}{ Women } \\
\hline & Current & Former & Ever & Current & Former & Ever & Current & Former & Ever & Current & Former & Ever \\
\hline $0-4$ & 0.0 & 0.0 & 0.0 & 0.0 & 0.0 & 0.0 & 0.0 & 0.0 & 0.0 & 0.0 & 0.0 & 0.0 \\
\hline $5-9$ & 0.0 & 0.0 & 0.0 & 0.0 & 0.0 & 0.0 & 0.0 & 0.0 & 0.0 & 0.0 & 0.0 & 0.0 \\
\hline $10-14$ & 1.0 & 0.0 & 1.0 & 0.5 & 0.0 & 0.5 & 2.5 & 0.0 & 2.5 & 0.9 & 0.0 & 0.9 \\
\hline $15-19$ & 7.0 & 0.0 & 7.0 & 2.5 & 0.0 & 2.5 & 18.8 & 0.0 & 18.8 & 5.5 & 0.0 & 5.5 \\
\hline $20-24$ & 44.4 & 3.2 & 47.7 & 15.4 & 3.5 & 19.0 & 52.3 & 3.9 & 56.2 & 17.6 & 2.9 & 20.5 \\
\hline $25-29$ & 52.3 & 8.4 & 60.6 & 20.7 & 7.3 & 28.0 & 63.9 & 5.5 & 69.4 & 17.5 & 6.1 & 23.6 \\
\hline $30-34$ & 54.7 & 10.0 & 64.7 & 19.6 & 9.8 & 29.4 & 56.0 & 9.6 & 65.6 & 16.3 & 5.1 & 21.4 \\
\hline $35-39$ & 55.3 & 13.8 & 69.1 & 16.0 & 8.0 & 24.0 & 59.1 & 11.5 & 70.6 & 16.8 & 4.5 & 21.3 \\
\hline $40-44$ & 49.7 & 20.2 & 69.9 & 14.5 & 7.0 & 21.6 & 58.0 & 16.6 & 74.6 & 14.5 & 4.3 & 18.8 \\
\hline $45-49$ & 44.9 & 24.7 & 69.6 & 13.9 & 5.2 & 19.1 & 56.2 & 19.8 & 76.0 & 12.0 & 2.4 & 14.4 \\
\hline $50-54$ & 48.1 & 24.7 & 72.8 & 13.6 & 4.7 & 18.3 & 55.5 & 21.3 & 76.8 & 11.0 & 2.1 & 13.2 \\
\hline $55-59$ & 43.4 & 27.6 & 71.1 & 10.2 & 2.9 & 13.1 & 49.0 & 24.2 & 73.2 & 7.9 & 2.8 & 10.6 \\
\hline $60-64$ & 37.7 & 29.5 & 67.2 & 8.7 & 3.8 & 12.5 & 42.2 & 30.1 & 72.3 & 7.2 & 1.9 & 9.1 \\
\hline $65-69$ & 30.1 & 30.5 & 60.6 & 5.5 & 2.9 & 8.3 & 34.7 & 38.2 & 73.0 & 6.8 & 1.9 & 8.7 \\
\hline $70-74$ & 24.2 & 35.1 & 59.3 & 4.5 & 2.7 & 7.1 & 34.2 & 42.6 & 76.8 & 4.2 & 3.2 & 7.4 \\
\hline$\geq 75$ & 18.8 & 35.3 & 54.1 & 2.5 & 3.1 & 5.7 & 26.9 & 48.1 & 75.0 & 3.2 & 2.5 & 5.7 \\
\hline Total & 40.8 & 23.5 & 64.4 & 11.1 & 4.9 & 15.9 & 47.6 & 25.0 & 72.6 & 10.6 & 3.2 & 13.7 \\
\hline
\end{tabular}

Data source: The National Health and Nutrition Survey, Japan, 2005. 
Table 2. Sex- and age-group-specific prevalence $(\%)$ of secondhand smoking in Japan in 2005

\begin{tabular}{lccccc}
\hline & \multicolumn{2}{c}{ Men } & & \multicolumn{2}{c}{ Women } \\
\cline { 2 - 3 } \cline { 5 - 6 } Age at exposure & At home & At work & & At home & At work \\
\cline { 2 - 3 } & & & & & \\
\hline $0-4$ & 6.2 & 0.0 & & 31.1 & 0.0 \\
$5-9$ & 6.2 & 0.0 & & 31.1 & 0.0 \\
$10-14$ & 6.2 & 0.0 & & 31.1 & 0.0 \\
$15-19$ & 6.2 & 29.4 & & 31.1 & 0.0 \\
$20-24$ & 6.2 & 29.4 & & 31.1 & 18.2 \\
$25-29$ & 6.2 & 29.4 & & 31.1 & 18.2 \\
$30-34$ & 6.2 & 29.4 & & 31.1 & 18.2 \\
$35-39$ & 6.2 & 29.4 & & 31.1 & 18.2 \\
$40-44$ & 6.2 & 29.4 & & 31.1 & 18.2 \\
$45-49$ & 6.2 & 29.4 & & 31.1 & 18.2 \\
$50-54$ & 6.2 & 29.4 & & 31.1 & 18.2 \\
$55-59$ & 6.2 & 29.4 & & 31.1 & 18.2 \\
$60-64$ & 6.2 & 29.4 & 31.1 & 18.2 \\
$65-69$ & 6.2 & 29.4 & 31.1 & 18.2 \\
$70-74$ & 6.2 & 29.4 & 31.1 & 18.2 \\
$\geq 75$ & & & & & \\
\hline
\end{tabular}

Data source: Report of the nationwide survey on adolescent smoking behavior in Japan, Grants-in-aid for the Comprehensive Health Sciences from the Ministry of Health, Labour, and Welfare, Japan. $2016(24)$.

\section{Estimation of relative risks}

The sources for the site-specific RR of cancer with relation to active smoking and SHS exposure are shown in Table 3. As a general rule, we prioritized metaanalyses or pooled analyses published for Japanese populations, followed by Asian populations, then studies from other nations. Studies that differentiated between current and past smokers were prioritized over studies that differentiated between ever- and non-smokers. RRs presented by sex were used. If the studies only presented RR for ever- or current smokers, these were used by considering the RR of former smokers to be 1 .

For SHS exposure at home, the summary RR was derived from a meta-analysis of Japanese studies; for SHS exposure at work, summary RR was derived from an international meta-analysis since a sufficient number of studies was not available for Japan.

\section{Estimation of population attributable fractions (PAFS)}

For active smoking, PAFs were calculated using the method of Levin's formula for multiple categories (29), proposed by Hanley (30). This method distinguishes between current and former smokers. PAF for active smoking was calculated for each sex and age group according to the formula:

$$
\mathrm{PAF}=\frac{P_{c}\left(R R_{c}-1\right)+P_{f}\left(R R_{f}-1\right)}{1+P_{c}\left(R R_{c}-1\right)+P_{f}\left(R R_{f}-1\right)}
$$

Where $P_{c}$ is the proportion of the population currently smoking, $R R_{c}$ is the RR for current smokers compared to never smokers, $P_{f}$ is the proportion of the population of former smokers, and $R R_{f}$ is the RR of former smokers compared to never smokers.

For SHS, PAF was calculated using the method described by Gan et al. (31). First, the PAF of nonsmokers exposure to SHS ( $\left.P A F_{\text {shns }}\right)$ was calculated using the following formula:

$$
P A F_{\text {shns }}=\frac{P(R R-1)}{1+P(R R-1)}
$$

Where $P$ and $R R$ refer to the proportion of SHS exposure and RR for non-smokers, respectively, compared to non-smokers who were not exposed to SHS. We then calculated the PAF for SHS $\left(P A F_{s h s}\right)$ for the entire population by:

$$
P A F_{\text {shs }}=P A F_{\text {shns }} \times\left(1-P A F_{c}\right) \times\left(1-P_{c}\right)
$$

Where $P A F_{c}$ refers to PAF of current smokers and $P_{c}$ refers to the proportion of current smokers in the population. PAF for SHS was only separated by gender; age groups were pooled due to the limited sample size and prevalence.

\section{Results}

Table 4 summarized the estimated PAF of cancer incidence and mortality in 2015 attributed to tobacco smoke in Japan.

Active smoking was estimated to have caused $23.6 \%$ of total cancer incidence among men and $4.0 \%$ among women. For major cancers, smoking caused $61.7 \%$ (men) and $20.9 \%$ (women) of lung cancer cases, and $57.5 \%$ (men) and 20.4\% (women) of esophageal cancer cases. Similarly, the estimated number and PAF of cancer mortality in 2015 attributed to active smoking were 29.8\% for men and $4.7 \%$ for women. For lung cancer deaths, $60.9 \%$ (men) and $18.3 \%$ (women) of cases may be attributable to smoking. For men and women combined, $15.2 \%$ of cancer incidence and $19.6 \%$ of cancer mortality in 2015 could be attributable to active tobacco smoking. Based on these results, 145,765 cases of cancer incidence $(129,502$ in men and 16,263 in women) (Table S1, online data, https://www.ghmopen.com/site/supplementaldata. html?ID=32) and 72,520 cancer deaths $(65,416$ in men and 7,105 in women) (Table S2, online data, https://www. ghmopen.com/site/supplementaldata.html? ID=32) were estimated to be attributable to active smoking.

Likewise, SHS was estimated to have caused $0.2 \%$ of total cancer incidence among men and $0.9 \%$ among women. Lung cancer incidence in 2015 attributable to SHS exposure at home and work in total was $1.3 \%$ (men) and 8.7\% (women). The PAFs for mortality were 
Table 3. Relative risk of cancer associated with passive and secondhand smoking compared with never smoking in Japan

\begin{tabular}{|c|c|c|c|c|}
\hline \multirow{2}{*}{ Cancer site (ICD-10 code) } & \multirow{2}{*}{ Exposure category } & \multicolumn{2}{|c|}{$\mathrm{RR}(95 \% \mathrm{CI})$} & \multirow{2}{*}{ Sources } \\
\hline & & Men & Women & \\
\hline \multicolumn{5}{|l|}{ Active smoking } \\
\hline \multirow[t]{2}{*}{ Oral cavity and pharynx (C00-C14) } & Current & $2.68(2.08-3.44)$ & $2.68(2.08-3.44)$ & Koyanagi et al. (Japanese meta-analysis) (11) \\
\hline & Former & $1.49(1.05-2.11)$ & $1.49(1.05-2.11)$ & \\
\hline \multirow[t]{2}{*}{ Esophagus (C15) } & Current & $3.73(2.16-6.43)$ & $3.73(2.16-6.43)$ & Oze et al. (Japanese meta-analysis) (43) \\
\hline & Former & $2.21(1.60-3.06)$ & $2.21(1.60-3.06)$ & \\
\hline \multirow[t]{2}{*}{ Stomach (C16) } & Current & $1.79(1.51-2.12)$ & $1.22(1.07-1.38)$ & Nishino et al. (Japanese meta-analysis) (44) \\
\hline & Former & - & - & \\
\hline \multirow[t]{2}{*}{ Colon (C18) } & Current & $1.18(1.06-1.31)$ & $1.12(0.96-1.31)$ & Akter et al. (Japanese pooled analysis) (15) \\
\hline & Former & $1.20(1.09-1.32)$ & $0.98(0.73-1.30)$ & \\
\hline \multirow[t]{2}{*}{ Rectum (C19-C20) } & Current & $1.27(1.12-1.44)$ & $1.05(0.83-1.34)$ & Akter et al. (Japanese pooled analysis) (15) \\
\hline & Former & $1.10(0.95-1.26)$ & $1.42(0.99-2.04)$ & \\
\hline \multirow[t]{2}{*}{ Liver (C22) } & Current & $1.81(1.49-2.20)$ & $1.73(1.21-2.48)$ & Katanoda et al. (Japanese pooled analysis) (6) \\
\hline & Former & $1.63(1.32-2.01)$ & $1.23(0.63-2.39)$ & \\
\hline Pancreas (C25) & Ever & $1.57(1.30-1.89)$ & $1.83(1.35-2.48)$ & Matsuo et al. (Japanese meta-analysis) (45) \\
\hline Nasal cavity (C30) & Ever & $2.49(1.86-3.34)$ & $3.12(1.62-5.99)$ & Koyanagi et al. (Japanese meta-analysis) (11) \\
\hline \multirow[t]{2}{*}{ Larynx (C32) } & Current & $5.47(1.29-23.11)$ & 1.00 & Katanoda et al. (Japanese pooled analysis) (6) \\
\hline & Former & $3.03(0.65-14.01)$ & 1.00 & \\
\hline \multirow[t]{2}{*}{ Lung (C33-C34) } & Current & $4.65(3.70-5.85)$ & $3.75(2.89-4.86)$ & Meta-analysis of Japanese studies (32) \\
\hline & Former & $2.38(1.86-3.05)$ & $2.96(1.92-4.56)$ & \\
\hline Cervix uteri (C53) & Ever & & $2.03(1.49-2.57)$ & Sugawara et al. (Japanese meta-analysis) (14) \\
\hline \multirow[t]{2}{*}{ Kidney (C64) } & Current & $1.57(0.81-3.06)$ & $0.60(0.08-4.47)$ & Katanoda et al. (Japanese pooled analysis) (6) \\
\hline & Former & $1.46(0.71-3.00)$ & $1.55(0.21-11.52)$ & \\
\hline \multirow[t]{3}{*}{ Renal pelvis and ureter (C65-C66) } & Current & $5.35(2.47-11.57)$ & & Katanoda et al. (Japanese pooled analysis) (6) \\
\hline & Former & $2.76(1.21-6.31)$ & & \\
\hline & Ever & & $1.30(0.59-2.88)$ & \\
\hline Bladder (C67) & Ever & $2.14(1.87-2.44)$ & $2.14(1.87-2.44)$ & Masaoka et al. (Japanese meta-analysis) (12) \\
\hline \multirow{2}{*}{$\begin{array}{l}\text { Acute myeloid leukemia (C92.0, } \\
\text { C92.4, C92.5) }\end{array}$} & Current & $1.44(0.97-2.14)$ & $1.44(0.97-2.14)$ & Ugai et al. (Japanese pooled analysis) (46) \\
\hline & Former & $1.42(0.91-2.22)$ & $1.42(0.91-2.22)$ & \\
\hline \multicolumn{5}{|l|}{ Secondhand smoking } \\
\hline \multirow{2}{*}{ Lung (C33-C34) } & Home & $1.28(1.10-1.48)$ & $1.28(1.10-1.48)$ & Hori et al. (Japanese meta-analysis) (16) \\
\hline & Workplace & $1.12(0.86-1.50)$ & $1.22(1.10-1.35)$ & Surgeon General Report meta-analysis (39) \\
\hline
\end{tabular}

$0.3 \%$ for men and $1.3 \%$ for women for total cancers, and $1.4 \%$ and $9.1 \%$ for lung cancer, respectively. For men and women combined, $0.5 \%$ of total cancer incidence $(3.7 \%$ of lung cancer) and $0.7 \%$ of total cancer mortality ( $3.6 \%$ of lung cancer) in 2015 were attributed to SHS. Based on these results, 4,579 cancer cases $(1,095$ in men and 3,483 in women; total number is not equal to the sum of men and women due to rounding) (Table S3, online data, https://www. ghmopen.com/site/supplementaldata.html? ID =32) and 2,667 cancer deaths (735 in men and 1,932 in women) (Table S4, online data, https://www.ghmopen.com/site/ supplementaldata.html?ID=32) were estimated to be attributable to SHS exposure.

\section{Discussion}

In this study, we estimated that in Japan, 145,765 (15.2\%) newly diagnosed cancer cases and 72,520 (19.6\%) cancer deaths in 2015 were attributable to active smoking. The PAFs were nearly $50 \%$ or even larger for lung, larynx, and esophagus for both cancer incidence and mortality. Men exhibited a much larger PAF of active smoking than women $(23.6 \%$ vs. $4.0 \%$ for incidence and $29.8 \% v s .4 .7 \%$ for mortality of total cancers). For SHS exposure, we estimated that $4,579(3.7 \%)$ cases of lung cancer incidence and 2,667 (3.6\%) lung cancer deaths were attributable in Japan annually. In contrast to active smoking, the PAF of SHS exposure was larger in women 
Table 4. Proportion (\%) of cancer in 2015 attributable to tobacco smoke in Japan

\begin{tabular}{|c|c|c|c|c|c|c|}
\hline \multirow{2}{*}{ Cancer Site (ICD-10) } & \multicolumn{3}{|c|}{ Incidence } & \multicolumn{3}{|c|}{ Mortality } \\
\hline & Men & Women & Both sexes & Men & Women & Both sexes \\
\hline \multicolumn{7}{|l|}{ Active tobacco smoking } \\
\hline Oral cavity and pharynx (C00-C14) & 43.4 & 13.3 & 34.1 & 41.8 & 10.0 & 32.6 \\
\hline Esophagus (C15) & 57.5 & 20.4 & 51.7 & 56.5 & 18.3 & 50.1 \\
\hline Stomach (C16) & 21.5 & 1.6 & 15.3 & 19.9 & 1.3 & 13.6 \\
\hline Colon (C18) & 10.8 & 0.9 & 6.2 & 10.6 & 0.7 & 5.6 \\
\hline Rectum (C19-C20) & 11.5 & 2.0 & 8.2 & 11.0 & 1.8 & 7.7 \\
\hline Liver (C22) & 31.9 & 5.2 & 22.6 & 31.3 & 3.4 & 21.8 \\
\hline Pancreas (C25) & 26.8 & 7.7 & 17.5 & 26.7 & 7.2 & 17.1 \\
\hline Nasal (C30-C31) & 48.9 & 19.7 & 38.8 & 48.4 & 17.1 & 36.4 \\
\hline Larynx (C32) & 68.5 & 0.0 & 63.6 & 66.7 & 0.0 & 61.7 \\
\hline Lung (C33-C34) & 61.7 & 20.9 & 48.5 & 60.9 & 18.3 & 48.8 \\
\hline Uterine cervix (C53) & & 15.6 & 15.6 & & 13.1 & 13.1 \\
\hline Kidney (C64) & 25.8 & 2.2 & 18.5 & 24.6 & 1.8 & 17.0 \\
\hline Renal pelvis and ureter (C65-C66) & 66.1 & 2.8 & 43.9 & 64.7 & 2.4 & 39.9 \\
\hline Bladder (C67) & 41.6 & 9.5 & 33.5 & 40.7 & 8.0 & 30.5 \\
\hline Acute myeloid leukemia (C92.0, C92.4, C92.5) & 20.6 & 5.3 & 14.5 & 21.2 & 4.4 & 14.8 \\
\hline Total & 23.6 & 4.0 & 15.2 & 29.8 & 4.7 & 19.6 \\
\hline \multicolumn{7}{|l|}{ Secondhand smoking } \\
\hline Lung (C33-C34) & 1.3 & 8.7 & 3.7 & 1.4 & 9.1 & 3.6 \\
\hline Total & 0.2 & 0.9 & 0.5 & 0.3 & 1.3 & 0.7 \\
\hline
\end{tabular}

than in men $(8.7 \%$ vs. $1.3 \%$ for incidence and $9.1 \% v s$. $1.4 \%$ for mortality of lung cancer). We reconfirmed that tobacco is still one of the major causes of cancer in Japan.

The PAFs estimated in the present study were slightly smaller than those reported in previously. In men, the PAF of cancer incidence attributable to active smoking was $29.7 \%$ in 2005 (5), which decreased to $23.6 \%$ in the present study (in 2015). A major reason for this is the decrease in smoking prevalence in Japan. Male ever smoking prevalence reduced from $72.9 \%$ (in 1990) (5) to 64.4\% (in 2005) in the present study. Our additional analysis showed that the PAF estimates were closely similar when we applied the same value for ever smoking prevalence (data not shown). Another factor is a change in methodology. First, we assumed a 10year latency period from exposure to outcome versus a 15 -year period in our previous study. In a sensitivity analysis we used a 15-year latency period instead (i.e. smoking prevalence in 2000), and found that the PAFs for all cancers combined were slightly larger, particularly for men (incidence: $26.3 \%$ for men, $4.0 \%$ for women, and $16.8 \%$ for men and women combined; mortality: $33.9 \%$ for men, $5.0 \%$ for women, and $22.1 \%$ for men and women combined). Second, we used age-specific smoking prevalence in the present study versus agepooled prevalence in the previous one (5). When we used age-pooled prevalence in the present study, the PAFs were slightly larger (e.g. $64.5 \%$ vs. $61.7 \%$ for male lung cancer incidence), probably due to overestimation of smoking prevalence among the elderly. Thus, the PAFs in men decreased due to both a decline in smoking prevalence and pooling age. By contrast, in women, although the PAF of cancer incidence attributable to active smoking reduced from $5.0 \%$ (in 2005) (5) to $4.0 \%$ in the present study (in 2015), ever smoking prevalence increased from $12.3 \%$ (in 1990) (5) to $15.9 \%$ (in 2005). However, when we applied age-pooled prevalence to the calculation, the PAF became larger (e.g. $28.6 \%$ vs. $20.9 \%$ for female lung cancer incidence). The effects of increased smoking prevalence and age-pooling in women were therefore balanced out.

The PAFs of lung cancer incidence attributable to SHS exposure in the present study were slightly smaller than those in our previous estimates $(1.3 \%$ vs. $1.6 \%$ for men, $8.7 \%$ vs. $12.6 \%$ for women) (5). The main reason is probably the decrease in the prevalence of SHS exposure, particularly at the workplace (men: $6.2 \%$ vs. $8 \%$ at home and $29.4 \%$ vs. $58 \%$ at workplace; women: $31.1 \%$ vs. $35 \%$ at home and $18.2 \%$ vs. $32 \%$ at workplace). Indeed, our PAF estimates were comparable to more recently published values (32,33). In April 2020, the revised Health Promotion Act came into force in Japan, by which indoor smoking at the workplace and in public places was partially banned. This legislative measure is expected to accelerate the decrease in SHS exposure, but the high prevalence of SHS exposure at home remains a major problem in Japan.

In men, our PAF estimates of active smoking in Japan were comparable to or larger than those in Western populations. According to recent publications, the PAF cancer incidence attributable to active smoking for men was $23.6 \%$ in United States (US) in 2014 (34), 17.7\% in United Kingdom (UK) in 2015 (35), and $15.8 \%$ in Australia in 2010 (36) (corresponding value was $23.3 \%$ in the present study). This reflects the 
higher male smoking prevalence in Japan, because the RR of lung cancer associated with active smoking was lower in Japanese than in Western populations (e.g. current smoking RR: 4.65 for men and 3.75 for women in Japan versus 8.96 for men and women in the UK study (35)). By contrast, in women, our PAF estimates of active smoking were smaller than those in Western populations (14.5\% in US (34), $12.4 \%$ in UK (35), $10.1 \%$ in Australia (36) (corresponding value was 3.8\% in the present study), reflecting the lower lung cancer RR and smaller female prevalence as well. The PAFs of active smoking reported in the Republic of Korea were comparable to our estimates $(20.8 \%$ in men and $1.0 \%$ in women for cancer incidence) (37), probably because of similar values for RR and smoking prevalence.

The strength of this study is the representativeness of the data. The data for smoking prevalence and SHS exposure were based on national representative surveys. Most of the RRs used here were derived from the latest meta-analysis or pooled large-scale cohort studies in the Japanese populations. The selection of causally related cancers was also based on an up-to-date and comprehensive review of the literature of Japanese population.

This study has some potential limitations. First, some of the RRs we used were based on values that were not sufficiently adjusted for confounding factors (i.e. liver, laryngeal and kidney cancers) (6). In particular, the RRs of liver cancer which were unadjusted for hepatitis $\mathrm{B}$ and $\mathrm{C}$ virus infection need to be interpreted with caution. However, the pooled RRs we used were close to those reported in a study that adjusted for these infectious factors (38). The RR we used for SHS exposure at the workplace was also not derived from a domestic meta-analysis but based on a value reported in the U.S. Surgeon General Report (39). However, this comprehensive review showed that there were no substantial geographical variation in the RR of SHS at the workplace (39).

Second, we only included cancers that were evaluated as "causally related to tobacco smoke exposure" in comprehensive evaluation reports. There are many other cancers that may potentially have causal link to tobacco. In that sense, the PAFs presented here are conservative estimates, which could be increased by future accumulation of scientific evidence.

Third, we assumed a 10-year latency period from exposure to outcome. Although this assumption was also adopted by many recent studies of PAF estimates $(35,36,40)$, latency from exposure to cancer occurrence is not well defined and could vary among cancers. We assumed that a longer lag time (15 years) resulted in larger PAF estimates for men, as stated above. Peto et al. proposed an alternative method that uses lung-cancer mortality as an indirect indicator of the accumulated hazards of smoking (41), which was adopted in the Global Bureau of Diseases Study $(1,42)$. However, we previously confirmed that this difference in methodology did not lead to any substantial changes in PAF estimates (6-8).

\section{Conclusion}

We estimated that in Japan, 145,765 (15.2\%) newly diagnosed cancer cases and 72,520 (19.6\%) cancer deaths in 2015 were attributable to active smoking. For SHS exposure, 4,579 cancer cases $(0.5 \%)$ and 2,667 cancer deaths $(0.7 \%)$ in 2015 were attributed to SHS. This result reconfirms that tobacco is still a major cause of cancer in Japan.

Funding: This study was supported by JSPS KAKENHI Grant Number 16H05244.

Conflict of Interest: The authors have no conflicts of interest to disclose.

\section{References}

1. GBD 2015 Risk Factors Collaborators. Global, regional, and national comparative risk assessment of 79 behavioral, environmental and occupational, and metabolic risks or clusters of risks, 1990-2015: a systematic analysis for the global burden of disease study 2015. Lancet. 2016; 388:1659-1724.

2. Drope J, Schluger N, Cahn Z, Drope J, Hamill S, Islami F, Liber A, Nargis N, Stoklosa M. The Tobacco Atlas Sixth Edition. American cancer society and vital strategies. https://tobaccoatlas.org/wp-content/uploads/2018/03/ TobaccoAtlas_6thEdition_LoRes_Rev0318.pdf (accessed October 20, 2021).

3. Eriksen M, Mackay J, Schluger N. The tobacco atlas fifth edition. American cancer society, 2015. https:// ncdalliance.org/sites/default/files/resource_files/ TA5_2015_WEB.pdf(accessed October 20, 2021).

4. Ministry of Health Labour and Welfare. National health and nutrition survey 2018. https://www.mhlw.go.jp/ content/000681200.pdf (accessed October 20, 2021). (in Japanese)

5. Inoue M, Sawada N, Matsuda T, Iwasaki M, Sasazuki S, Shimazu T, Shibuya K, Tsugane S. Attributable causes of cancer in Japan in 2005 - systematic assessment to estimate current burden of cancer attributable to known preventable risk factors in Japan. Ann Oncol. 2012; 23:1362-1369.

6. Katanoda K, Marugame T, Saika K, Satoh H, Tajima K, Suzuki T, Tamakoshi A, Tsugane S, Sobue T. Population attributable fraction of mortality associated with tobacco smoking in Japan: a pooled analysis of three large-scale cohort studies. J Epidemiol. 2008; 18:251-264.

7. Ikeda $\mathrm{N}$, Inoue $\mathrm{M}$, Iso $\mathrm{H}$, et al. Adult mortality attributable to preventable risk factors for non-communicable diseases and injuries in Japan: a comparative risk assessment. PLoS Med. 2012; 9:e1001160.

8. Murakami Y, Miura K, Okamura T, Ueshima H; EPOCHJAPAN Research Group. Population attributable numbers and fractions of deaths due to smoking: a pooled analysis of 180,000 Japanese. Prev Med. 2011; 52:60-65. 
9. Japanese Committee on Health Effects of Smoking. Smoking and health report. https://www.mhlw.go.jp/ content/000550455.pdf (accessed October 20, 2021). (in Japanese)

10. Office of the Surgeon General (US), Office on Smoking and Health (US), Centers for Disease Control and Prevention (US). The health consequences of smoking: a report of the Surgeon General. 2004. https://www.cdc. gov/tobacco/data_statistics/sgr/2004/index.htm (accessed October 20, 2021)

11. Koyanagi $\mathrm{YN}$, Matsuo $\mathrm{K}$, Ito $\mathrm{H}$, et al. Cigarette smoking and the risk of head and neck cancer in the Japanese population: a systematic review and meta-analysis. Jpn J Clin Oncol. 2016; 46:580-595.

12. Masaoka $\mathrm{H}$, Matsuo $\mathrm{K}$, Ito $\mathrm{H}$, et al. Cigarette smoking and bladder cancer risk: an evaluation based on a systematic review of epidemiologic evidence in the Japanese population. Jpn J Clin Oncol. 2016; 46:273-283.

13. Ugai T, Matsuo K, Oze I, et al. Smoking and subsequent risk of acute myeloid leukaemia: A pooled analysis of 9 cohort studies in Japan. Hematol Oncol. 2018; 36:262268.

14. Sugawara Y, Tsuji I, Mizoue T, et al. Cigarette smoking and cervical cancer risk: an evaluation based on a systematic review and meta-analysis among Japanese women. Jpn J Clin Oncol. 2019; 49:77-86.

15. Akter S, Islam Z, Mizoue T, et al. Smoking and colorectal cancer: A pooled analysis of 10 population-based cohort studies in Japan. Int J Cancer. 2021; 148:654-664.

16. Hori M, Tanaka H, Wakai K, Sasazuki S, Katanoda K. Secondhand smoke exposure and risk of lung cancer in Japan: a systematic review and meta-analysis of epidemiologic studies. Jpn J Clin Oncol. 2016; 46:942951.

17. Japan Health Promotion \& Fitness Foundation. Smoking prevalence. http://www.health-net.or.jp/tobacco/menu02. html (accessed October 20, 2021). (in Japanese)

18. Secretan B, Straif K, Baan R, Grosse Y, El Ghissassi F, Bouvard V, Benbrahim-Tallaa L, Guha N, Freeman C, Galichet L, Cogliano V; WHO International Agency for Research on Cancer Monograph Working Group. A review of human carcinogens - Part E: tobacco, areca nut, alcohol, coal smoke, and salted fish. Lancet Oncol. 2009; 10:1033-4.

19. Iarc Working Group on the Evaluation of Carcinogenic Risks to Humans. Personal habits and indoor combustions. Volume $100 \mathrm{E}$. A review of human carcinogens. IARC Monogr Eval Carcinog Risks Hum. 2012; 100:1-538.

20. National Center for Chronic Disease Prevention and Health Promotion (US) Office on Smoking and Health. The health consequences of smoking - 50 years of progress: a report of the surgeon general. Atlanta (GA): Centers for Disease Control and Prevention (US); 2014.

21. Sasazuki S, Inoue M, Shimazu T, et al. Evidence-based cancer prevention recommendations for Japanese. Jpn J Clin Oncol. 2018; 48:576-586.

22. Ministry of Health Labour and Welfare. National health and nutrition survey 2005. https://www.mhlw.go.jp/bunya/ kenkou/eiyou07/01.html (accessed October 20, 2021). (in Japanese)

23. Ministry of Health Labour and Welfare. National nutrition survey 2000. https://www.mhlw.go.jp/toukei/kouhyo/ indexkk 14 7.html (accessed October 20, 2021). (in Japanese)

24. Hayashi K. Nationwide survey on adolescent smoking behavior in Japan. In: Grants-in-aid for the Comprehensive Health Sciences from the Ministry of Health, Labour, and Welfare. 2005. (fiscal year 2004) https://mhlw-grants. niph.go.jp/project/10515 (accessed October 20, 2021) (in Japanese)

25. Cancer Statistics. Cancer Information Service, National Cancer Center, Japan (Monitoring of cancer incidence in Japan (MCIJ)) https://ganjoho.jp/reg_stat/statistics/data/ dl/en.html (accessed October 20, 2021).

26. Katanoda K, Kamo K, Saika K, Matsuda T, Shibata A, Matsuda A, Nishino Y, Hattori M, Soda M, Ioka A, Sobue T, Nishimoto H. Short-term projection of cancer incidence in Japan using an age-period interaction model with spline smoothing. Jpn J Clin Oncol. 2014; 44:36-41.

27. Cancer Statistics. Cancer Information Service, National Cancer Center, Japan (Vital Statistics of Japan, Ministry of Health, Labour and Welfare) https://ganjoho.jp/reg stat/statistics/data/dl/en.html (accessed October 20, 2021).

28. Ministry of Health Labour and Welfare. Sex and age specific mortality statistics in Japan (2015) by ICD-10, by 4-digit. Health, Labour and Welfare Statistics Association. http://www.hws-kyokai.or.jp/information/mortality.html (accessed October 20, 2021). (in Japanese)

29. Levin ML. The occurrence of lung cancer in man. Acta Unio Int Contra Cancrum. 1953; 9:531-541.

30. Hanley JA. A heuristic approach to the formulas for population attributable fraction. J Epidemiol Community Health. 2001; 55:508-514.

31. Gan Q, Smith KR, Hammond SK, Hu TW. Disease burden of adult lung cancer and ischaemic heart disease from passive tobacco smoking in China. Tob Control. 2007; 16:417-422.

32. Hori M, Saito E, Katanoda K, Tsugane S. Estimation of lifetime cumulative mortality risk of lung cancer by smoking status in Japan. Jpn J Clin Oncol. 2020; 50:12181224.

33. Research on the comprehensive evaluation of the health and economic effects of tobacco smoking and tobacco control. Report of the Grant-in-Aid for the Comprehensive Research on Life-Style Related Diseases including Cardiovascular Diseases and Diabetes Mellitus by Ministry of Health, Labour and Welfare. 2016 (fiscal year 2015) https://mhlw-grants.niph.go.jp/project/25303 (accessed October 20, 2021). (in Japanese)

34. Islami F, Goding Sauer A, Miller KD, Siegel RL, Fedewa SA, Jacobs EJ, McCullough ML, Patel AV, Ma J, Soerjomataram I, Flanders WD, Brawley OW, Gapstur SM, Jemal A. Proportion and number of cancer cases and deaths attributable to potentially modifiable risk factors in the United States. CA Cancer J Clin. 2018; 68:31-54.

35. Brown KF, Rumgay H, Dunlop C, et al. The fraction of cancer attributable to modifiable risk factors in England, Wales, Scotland, Northern Ireland, and the United Kingdom in 2015. British journal of cancer. 2018; 118:1130-1141.

36. Whiteman DC, Webb PM, Green AC, et al. Cancers in Australia in 2010 attributable to modifiable factors: summary and conclusions. Aust N Z J Public Health. 2015; 39:477-484.

37. National Cancer Center Korea. Attributable causes of cancer in Korea in the year 2009.

38. Tanaka K, Tsuji I, Wakai K, Nagata C, Mizoue T, Inoue M, Tsugane S; Research Group for the Development and Evaluation of Cancer Prevention Strategies in Japan. Cigarette smoking and liver cancer risk: an evaluation 
based on a systematic review of epidemiologic evidence among Japanese. Jpn J Clin Oncol. 2006; 36:445-456.

39. U.S. Department of Health and Human Services, Centers for Disease Control and Prevention, Coordinating Center for Health Promotion, National Center for Chronic Disease Prevention and Health Promotion, Office on Smoking and Health. The Health Consequences of Involuntary Exposure to Tobacco Smoke: A Report of the Surgeon General. 2006. https://www.cdc.gov/tobacco/ data_statistics/sgr/2006/index.htm (accessed October 20, 2021).

40. Parkin DM, Boyd L, Walker LC. 16. The fraction of cancer attributable to lifestyle and environmental factors in the UK in 2010. Br J Cancer. 2011; 105 Suppl 2(Suppl 2):S77-81.

41. Peto R, Lopez AD, Boreham J, Thun M, Heath C Jr. Mortality from tobacco in developed countries: indirect estimation from national vital statistics. Lancet. 1992; 339:1268-1278.

42. Ezzati M, Lopez AD. Estimates of global mortality attributable to smoking in 2000. Lancet. 2003; 362:847852.

43. Oze I, Matsuo K, Ito H, Wakai K, Nagata C, Mizoue T, Tanaka K, Tsuji I, Tamakoshi A, Sasazuki S, Inoue M, Tsugane S; Research Group for the Development and Evaluation of Cancer Prevention Strategies in Japan. Cigarette smoking and esophageal cancer risk: an evaluation based on a systematic review of epidemiologic evidence among the Japanese population. Jpn J Clin Oncol. 2012; 42:63-73.

44. Nishino Y, Inoue M, Tsuji I, Wakai K, Nagata C, Mizoue T, Tanaka K, Tsugane S; Research Group for the Development and Evaluation of Cancer Prevention
Strategies in Japan. Tobacco smoking and gastric cancer risk: an evaluation based on a systematic review of epidemiologic evidence among the Japanese population. Jpn J Clin Oncol. 2006; 36:800-807.

45. Matsuo K, Ito H, Wakai K, Nagata C, Mizoue T, Tanaka K, Tsuji I, Tamakoshi A, Sasazuki S, Inoue M, Tsugane $\mathrm{S}$; Research Group for the Development and Evaluation of Cancer Prevention Strategies in Japan. Cigarette smoking and pancreas cancer risk: an evaluation based on a systematic review of epidemiologic evidence in the Japanese population. Jpn J Clin Oncol. 2011; 41:12921302.

46. Ugai T, Matsuo K, Sawada N, Iwasaki M, Yamaji T, Shimazu T, Sasazuki S, Inoue M, Kanda Y, Tsugane S; Japan Public Health Centre-based Prospective Study Group. Smoking and alcohol and subsequent risk of myelodysplastic syndromes in Japan: the Japan public health centre-based prospective study. Br J Haematol. 2017; 178:747-755.

Received June 11, 2021; Revised October 29, 2021; Accepted December 3, 2021.

Released online in J-STAGE as advance publication December 11, 2021.

*Address correspondence to:

Kota Katanoda, Division of Cancer Statistics Integration, Center for Cancer Control and Information Services, National Cancer Center. 5-1-1 Tsukiji, Chuo-ku, Tokyo 104-0045, Japan.

E-mail: kkatanod@ncc.go.jp 